\title{
Impact of dietary counselling on nutrient intake during pregnancy: a prospective cohort study
}

\author{
T. Piirainen ${ }^{1,2}$, E. Isolauri ${ }^{2,3}, \mathrm{H}$. Lagström ${ }^{4}$ and K. Laitinen ${ }^{1,2}$ \\ ${ }^{1}$ Department of Biochemistry and Food Chemistry and Functional Foods Forum, University of Turku, Itäinen Pitkäkatu 4 A, \\ 5th floor, 20520 Turku, Finland \\ ${ }^{2}$ Department of Paediatrics, Turku University Central Hospital, Turku, Finland \\ ${ }^{3}$ Department of Paediatrics, University of Turku, Turku, Finland \\ ${ }^{4}$ Department of Paediatrics and Cardiorespiratory Research Unit, Turku University Central Hospital, Turku, Finland
}

(Received 20 February 2006 - Revised 30 June 2006 - Accepted 31 July 2006)

\begin{abstract}
The aim of this study was to assess the impact of dietary counselling combined with the provision of food products on food and nutrient intake in pregnant women. We carried out a prospective cohort study of healthy and atopic pregnant women ( $n$ 209), who were randomized into dietary intervention and control groups. The intervention group received dietary counselling and food products to modify the fat composition of their diet to meet current recommendations. Three-day food records were collected during each trimester of pregnancy. Women in the intervention group consumed more vegetables, fruits, soft margarines and vegetable oils and less butter than those in the control group during the course of pregnancy $(P<0 \cdot 05)$. The main distinction between the groups in nutrient intake over the pregnancy was attributable to a higher energy intake (\% energy) of PUFA by $0.5 \%$ energy $(95 \%$ CI $0 \cdot 1,0 \cdot 8)$ and to a lower intake of SFA by $0.8 \%$ energy $(95 \%$ CI $-1.4,-0.4)$ in the intervention group. Dietary intake of vitamin E was $1.4 \mathrm{mg}(95 \% \mathrm{CI} 0 \cdot 6,2 \cdot 2)$, folate $20.9 \mu \mathrm{g}(95 \% \mathrm{CI} 0 \cdot 8,41 \cdot 0)$ and ascorbic acid $19.8 \mathrm{mg}(95 \% \mathrm{CI}$ $3.5,36 \cdot 0)$ higher in the intervention group compared to the controls, while no differences in other nutrients were detected. Dietary counselling combined with the provision of food products during pregnancy is of importance in modifying food and nutrient intake, with potential health benefits.
\end{abstract}

Pregnancy: Diet: Food consumption: Fat: Nutrient intake: Dietary counselling: Atopic disease

In the search for factors contributing to the increasing burden of chronic diseases in developed countries, research interest has focused on nutrition from as early as fetal life. Fetal nutrition may influence the subsequent risk of chronic childhood and adult diseases, among them CHD, hypertension and non-insulin-dependent diabetes (Godfrey \& Barker, 2000). Unbalanced food intake together with metabolic changes occurring during pregnancy may influence the mother's health in increasing the risk of obesity, which may be a risk factor for metabolic conditions including gestational diabetes mellitus and hypertension (Pallard et al. 1999; Vasan et al. 2001; Verma et al. 2002), pregnancy weight increase being the strongest predictor of sustained weight retention (Rössner \& Öhlin, 1995; Gunderson et al. 2000).

Despite the importance of maternal nutrition on fetal wellbeing, only limited data are available on nutrient intake and nutrient requirements during pregnancy, and prospective studies, in particular, are lacking. Thus recommendations for dietary intake and even for weight gain during pregnancy are inconsistent (Abrams et al. 2000) and there are no specific dietary recommendations for women with allergic disease. Mothers with atopic disease may restrict their diet due to symptoms of the disease (Hoppu et al. 2000) and additionally they may modify their diet to reduce the risk of the disease in the infant (Sicherer, 2002). Likewise, irrespective of the mother's own atopic disease status, manipulation of the maternal diet has been a common practice in an attempt to reduce the risk of disease in the infant (Arvola \& Holmberg-Marttila, 1999). This may, however, result in an unbalanced diet and even increase the risk of atopic disease in the child, as was shown in a study where maternal high intake of SFA during breast-feeding was associated with atopic sensitization of the infant (Hoppu et al. 2000).

Dietary counselling of pregnant and breast-feeding mothers would be of importance in effecting nutrient intake potentially beneficial to both the mother and the child. To implement such counselling for populations of pregnant women, further information is needed on both the requirements of nutrients during pregnancy and the effects of counselling on the intake of foods and nutrients. The present study was undertaken to assess the impact of dietary counselling on dietary intake in a prospective cohort study of pregnant women. The counselling was designed to modify dietary intake to that recommended at the time of study initiation (Nordic Nutrition Recommendations, NNR;

Abbreviations: NNR, Nordic Nutrition Recommendations.

* Corresponding author: T. Piirainen, email tarja.piirainen@utu.fi 
Nordic Working Group on Diet \& Nutrition, 1996), with a particular focus on the amount and type of fat in the diet, and to ensure the growth and development of the fetus.

\section{Subjects and methods}

\section{Subjects and study design}

The study population comprised pregnant women participating in a prospective ongoing mother and infant nutrition and probiotic study. Women were recruited at their first visit to a maternal welfare clinic in the city of Turku and neighbouring areas in South-West Finland. The subjects were healthy and had no chronic or metabolic diseases, although those with an atopic disease were included. At entry they were randomized to a dietary intervention group receiving dietary counselling and food products and a control group. A total of 231 pregnant women were recruited, 215 of whom attended all study visits at each trimester of pregnancy. Of these subjects, 140 were randomized to the dietary intervention and sixty-nine to the control group. Additionally, the women in the intervention group were randomized in a double-blind manner to receive either probiotic or placebo capsules (which do not contain any nutrients) and the controls received placebo. The reasons for discontinuing the study were: miscarriage ( $n$ 4); moving to another town ( $n$ 1); diseases not related to pregnancy (migraine, mental problems; $n 4)$; no particular reason $(n 7)$. One woman in the first and the second and four women in the third trimester of pregnancy failed to complete food records and were excluded, leaving a total of 209 women in the final analysis. Written informed consent was obtained from the women, and the study was approved by the Ethical Committee of the Hospital District of South-West Finland.

\section{Clinical evaluation}

Height at the first research visit and weight and blood pressure at each visit were measured by a nurse. Weight prior to pregnancy was self-reported and used for calculation of pre-pregnancy BMI as weight $(\mathrm{kg})$ divided by the square of the height $\left(\mathrm{m}^{2}\right)$. Women were classified according to BMI (World Health Organization, 1988) as underweight (BMI $<20.0 \mathrm{~kg} / \mathrm{m}^{2}$ ), normal weight $\left(20 \cdot 0 \mathrm{~kg} / \mathrm{m}^{2} \leq\right.$ BMI $\left.<25 \cdot 0 \mathrm{~kg} / \mathrm{m}^{2}\right)$, overweight $\left(25 \cdot 0 \mathrm{~kg} / \mathrm{m}^{2} \leq \mathrm{BMI}<30 \cdot 0 \mathrm{~kg} / \mathrm{m}^{2}\right)$ or obese $\left(\mathrm{BMI}>30 \mathrm{~kg} / \mathrm{m}^{2}\right)$. Total gestational weight gain was calculated by subtracting selfreported pre-pregnancy weight from the weight recorded at the prenatal visit or at hospital within one week before delivery. Energy requirements were estimated using pre-pregnancy weight, a physical activity level of 1.56 and $285 \mathrm{kcal}$ being added during the second and third trimester of pregnancy (World Health Organization, 1985). Information on age, smoking, parity, education and all episodes of aerobic physical activity exceeding $30 \mathrm{~min}$ a time were obtained by interview. Birth data on the infants were obtained from hospital records.

Atopic disease in the pregnant women was defined as a history of self-reported atopic eczema, allergic rhinitis, asthma or adverse reactions to foods together with a positive skin prick test result measured at the last trimester of pregnancy, as described previously (Kalliomäki et al. 2001; Laitinen et al. 2006).

\section{Dietary counselling and food products}

At each study visit women in the intervention group were given detailed dietary counselling by a nutritionist aiming to modify dietary intake to comply with that recommended for pregnant women at the time of initiation of the study in 2002 (NNR; Nordic Working Group on Diet \& Nutrition, 1996). Specifically, dietary counselling focused on the amount and the type of fat and the amount of fibre in the diet. The subjects were encouraged to increase their consumption of vegetables, fruits and wholegrain bread and cereals, to consume leaner meat products, low-fat cheese and milk products, and to use vegetable oil or soft margarine as a spread and in food preparation. Fish was recommended as one of the main meals twice a week. Practical dietary advice was given, adjusted to the women's current dietary habits and food diary analysis. Achievement of the recommended diet was supported by providing the mothers with conventional food products with favourable fat (e.g. low erucic acid rapeseed oilbased spreads and salad dressing) and fibre content (e.g. fibre-enriched pasta, breakfast muesli and porridge cereals) for use at home. The consumption of specified amounts of the food products was advised, but adjustment for current dietary habits was allowed. The recommended amounts of foods were planned to provide $19 \mathrm{~g}$ of MUFA and $19 \mathrm{~g}$ of PUFA. This, combined with the advised consumption of other foods, would result in MUFA contributing $10-15 \%$ of energy intake (\% energy), PUFA 5-10 \% energy and SFA 10 $\%$ energy or less. Total intake of fat would be $30 \%$ energy, carbohydrates 55-60\% energy and protein 10-15\% energy. Compliance with consuming the food products was evaluated by comparing their consumption with those advised immediately before study visits assessed by 3-day food records and overall use during the 12-week period between the study visits by interview.

\section{Food records}

Food and nutrient intakes were assessed using 3-day, including one weekend day, food records with household measures at each trimester of pregnancy. The subjects were given personal and written instructions on recording, and the records were reviewed for completeness and accuracy by a nutritionist with the aid of a portion picture booklet. If needed, missing portion sizes and food descriptions were added after discussions with the women, and the type, brand and preparation method of all foods used were recorded. Daily energy and nutrient intakes were calculated using the Micro-Nutrica ${ }^{\circledR}$ computerized program version 2.5 (Research Centre of the Social Insurance Institution, Turku, Finland), which uses the Food and Nutrient Database of the Social Insurance Institution and is continuously updated with data on commercial foods. Both groups received written feedback of the calculation and the intervention group also received advice on how to alter the diet to conform better to the recommended diet. Data on use of vitamin and mineral supplements were obtained by interview and the intakes of nutrients from the supplements were calculated separately. 


\section{Statistics}

Results are presented as mean and standard deviation (SD) or mean with $95 \%$ CI or proportions of the cohort. For baseline characteristics, the group means were compared by independent-samples $t$ test for continuous variables tested for normal distribution by the Shapiro-Wilk test, and by Pearson $\chi^{2}$ test or Fisher's exact test for dichotomous variables. Pearson's correlation coefficient analysis was used to evaluate the association between energy intake and total gestational weight gain. Repeated-measures ANOVA was performed to establish any significant difference between intervention and control groups for dietary variable, and also by time (over the pregnancy), and time $\times$ group interactions for estimated energy requirement, blood pressure and physical activity. Huynh-Feldt adjustment was performed if the Maucly's Test of Sphericity $P$ value was less than $0 \cdot 05$. Differences between the groups at each trimester were further examined by calculating $95 \%$ CI. Significant timex group interactions were further examined by reanalysing the effect of the time factor within the intervention or control group with repeated-measures ANOVA to establish whether changes during pregnancy differed between women receiving and women not receiving dietary counselling. When significant time $\times$ group interactions were detected, $95 \%$ CI were calculated for mean differences between trimesters to ascertain the timing of the change. The effects of women's pre-pregnancy BMI and episodes of aerobic physical activity on energy intake were evaluated by adding them to the analysis as a covariate. The impact of atopic disease on dietary intake was evaluated by independent-samples $t$ test at first study visit as dietary counselling did not influence differently women with or without atopic disease. The level of significance used was $P<0.05$. All statistical analyses were performed with the Statistical Package for the Social Sciences version 12.0.1 (SPSS Inc., Chicago, IL, USA).

\section{Results}

\section{Subject characteristics}

The baseline characteristics of the women in the intervention and control groups were similar (Table 1). The women attended study visits at each trimester of pregnancy, the first at a mean of 14 (median 14, range 7.4-7.7), the second at 24 (median 24, range 20.1-27.3) and the third at 34 (median 34, range 30.1-37.1) weeks of gestation. Of the women, $12 \%$ were underweight, $61 \%$ normal weight, $21 \%$ overweight and $7 \%$ obese as assessed by pre-pregnancy BMI ( $P=0.98$ between the groups). A positive skin prick test result was detected in $58 \%$ of the women. The most common positive skin prick test reactions were for birch (69\% of the positive test results), cat $(68 \%)$, alder $(64 \%)$, grasses $(61 \%)$ and $\operatorname{dog}(50 \%)$. A positive skin prick test result for foods was detected in $12 \%$ of the women, the most common of which were for peanut $(13 \%$ of the positive test results), hazelnut $(10 \%)$, potato $(7 \%)$, carrot $(6 \%)$ and $\operatorname{cod}(3 \%)$. Altogether, $55 \%(n 75)$ of the women in the intervention and $56 \%$ ( $n$ 38) in the control group $(P=0.48$ between the groups) had atopic disease, defined as a history of selfreported atopic eczema, allergic rhinitis, asthma or adverse reaction to foods together with a positive skin prick test result.

\section{Evolution of pregnancy and physical activity}

During the course of the study, 207 women delivered healthy singleton infants and two delivered twins. The mean gestational length was 40.0 (SD 1.3) weeks $(P=0.76$ between the groups) and the total gestational weight gain was 14.9 (SD 4.9$) \mathrm{kg}(P=0.86$ between the groups). The mean birth weight of the infants was 3547 (SD 438) g $(P=0.20$ between the groups), length 51 (SD 2) $\mathrm{cm}(P=0.61$ between the groups) and head circumference 35 (SD 1) $\mathrm{cm} \quad(P=0 \cdot 14$ between the groups).

The women in both groups were normotensive as evaluated by mean baseline blood pressure measurements (Table 1). In evaluation of the evolution of blood pressure during pregnancy, both systolic $[1.7 \mathrm{mmHg}(95 \% \mathrm{CI}-3.2,-0.2)$ from the first to the third trimester; $P=0.02$ time effect] and diastolic $[1.8 \mathrm{mmHg}(95 \% \mathrm{CI}-3.1,-0.6)$ from the first to the second trimester; $P=0.005$ time effect] blood pressure decreased in all women (group effect $P=0.23$ for systolic and $P=0.93$ for diastolic blood pressure).

In the intervention group there were 1.9 (95\% CI 1.6, 2.2) weekly episodes of aerobic physical activity exceeding $30 \mathrm{~min}$

Table 1. Baseline characteristics of the women in the intervention ( $n$ 140) and the control $(n 69)$ groups

(Values are means with their standard deviation or number and percentage)

\begin{tabular}{|c|c|c|c|c|c|c|c|c|c|}
\hline & \multicolumn{4}{|c|}{ Intervention group } & \multicolumn{4}{|c|}{ Control group } & \multirow[b]{2}{*}{$P^{\star}$} \\
\hline & Mean & SD & $n$ & $\%$ & Mean & $\mathrm{SD}$ & $n$ & $\%$ & \\
\hline Age (years) & $29 \cdot 7$ & 4.6 & & & $29 \cdot 8$ & 4.7 & & & 0.86 \\
\hline $\begin{array}{l}\text { Pre-pregnancy BMI }\left(\mathrm{kg} / \mathrm{m}^{2}\right) \\
\text { Blood pressure }(\mathrm{mmH})\end{array}$ & $23 \cdot 4$ & $3 \cdot 6$ & & & $23 \cdot 5$ & 3.5 & & & 0.73 \\
\hline Systolic & 114.9 & $11 \cdot 4$ & & & $115 \cdot 8$ & $10 \cdot 2$ & & & 0.61 \\
\hline Diastolic & 68.4 & 8.9 & & & 69.7 & $7 \cdot 3$ & & & 0.26 \\
\hline \multicolumn{10}{|l|}{ Smoking } \\
\hline Before pregnancy & & & 48 & 35 & & & 23 & 34 & 0.51 \\
\hline During pregnancy & & & 3 & 2 & & & 2 & 3 & 0.54 \\
\hline \multicolumn{10}{|l|}{ Parity } \\
\hline Primigravida & & & 81 & 58 & & & 39 & 57 & 0.49 \\
\hline \multicolumn{10}{|l|}{ Education } \\
\hline University or college & & & 65 & 47 & & & 36 & 52 & 0.53 \\
\hline
\end{tabular}

${ }^{*}$ Independent-samples $t$ test for continuous variables and $\chi^{2}$ test or Fisher's exact test for dichotomous variables. 
a time in the first, 1.4 (95\% CI $1.1,1.7)$ in the second and 1.6 (95\% CI $1.2,2.0)$ in the third trimester of pregnancy; in the control group the corresponding frequencies were $2 \cdot 2$ $(95 \%$ CI $0.9,2.1), 1.5(95 \%$ CI $1.7,2.8)$ and $1.0(95 \% \mathrm{CI}$ $0.5,1.5)(P<0.001$ time effect, $P=0.03$ interaction time by group, $P=0.84$ group effect). Aerobic physical activity decreased by $1.3(95 \%$ CI $-2.0,-0.7)$ episodes per week by the third trimester of pregnancy in the control group only, while no change was observed in the intervention group.

\section{Impact of atopic disease on dietary intake}

When evaluating the impact of atopic disease on dietary intake before the onset of intervention, the intake of MUFA was $2.3 \mathrm{~g}$ (95\% CI $0.1,4.4 ; P=0.039$ ) and that of vitamin E $0.9 \mathrm{mg}$ (95\% CI $0.7,1.8 ; P=0.034)$ and consumption of margarines $3.9 \mathrm{~g}(95 \%$ CI $1.5,6.3 ; P=0.001)$ higher in women with atopic disease compared to those without. No differences in intakes of other foods or nutrients between women with and without atopic disease were detected (data not shown).

\section{Compliance in consumption of the food products provided}

According to the interviews, the proportion of women who consumed the food products provided for each 12-week period between study visits ranged from $68 \%$ to $100 \%$ depending on the product (Table 2). However, as assessed by 3-day food records filled in immediately before the study visits, fewer women (39-81\%) had, except for spreads, consumed the provided food products. In addition to the habitual intake, the products provided $6.9 \mathrm{~g}$ (95\% CI 5.9, 7.9) MUFA and $2.9 \mathrm{~g}(95 \% \mathrm{CI} 2.3,2.9)$ PUFA in the second trimester and $6.9 \mathrm{~g}(95 \% \mathrm{CI} 6.1,7.8)$ MUFA and $2.6 \mathrm{~g}$ (95\% CI 2.3 , 2.9) PUFA in the third trimester of pregnancy, this being $36 \%$ and $14 \%$, respectively, of the counselled intake for both trimesters. However, for evaluation of compliance, the intake of MUFA and PUFA is likely to be underestimated as the consumption of rapeseed oil incorporated in food recipes could not be calculated separately.

\section{Impact of dietary intervention on dietary intake}

Consumption of foods in the intervention and control groups is shown in Table 3. Changes in food consumption during pregnancy were detected only in the intervention group, and were attributable to higher consumption of vegetables by $23 \mathrm{~g} \mathrm{(95 \%}$ CI $1.4,44.7)$, fruits by $59 \mathrm{~g}$ (95\% CI 28.1, 89.9), soft margarines by $2.9 \mathrm{~g}(95 \%$ CI $1 \cdot 0,4 \cdot 7)$ and vegetable oils by $2.6 \mathrm{~g}(95 \%$ CI $0.9,4 \cdot 3)$, and lower consumption of butter by $3.0 \mathrm{~g}(95 \% \mathrm{CI}-4.0,-2.0)$ in the intervention group during the course of pregnancy. Although no differences were observed between the groups in consumption of fish, meat or cheese over the pregnancy, in the third trimester the intervention group consumed $9.2 \mathrm{~g}(95 \%$ CI $0.5,18.0)$ more fish and $15.0 \mathrm{~g}(95 \% \mathrm{CI}-29.5,-0.3)$ less meat and $13.0 \mathrm{~g}$ ( $95 \%$ CI $-21.3,-5.4)$ less cheese than the control group.

The mean daily intake of energy as a proportion of the estimated energy requirement was $89 \%(95 \%$ CI 86, 93) and $85 \%(95 \%$ CI 80,90$)$ in the first, $80 \%(95 \%$ CI 77,88$)$ and $76 \%(95 \%$ CI 72,81$)$ in the second, and $78 \%(95 \%$ CI 75,81$)$ and $75 \%(95 \%$ CI 80, 84) in the third trimester of pregnancy in the intervention and the control groups, respectively $(P=0.29$ group effect). Independent of the group, the intake of energy as a proportion of estimated requirement decreased from the first to the third trimester of pregnancy by $9.5 \%$ (95\% CI $-12.3,-6.8 ; P<0.001$ time effect). Total weight gain during pregnancy was positively associated with energy intake in the first $(R 0.15, P=0.035$, $n$ 201) and the second $(R 0 \cdot 15, P=0 \cdot 035, n$ 201) but not in the third trimester $(R 0 \cdot 11, P=0 \cdot 118, n$ 201). Episodes of aerobic physical activity and pre-pregnancy BMI did not affect the energy intake during pregnancy.

Intakes of energy and energy-yielding nutrients in the intervention and control groups at each trimester of pregnancy are presented in Table 4. The distinction between the groups in the overall intakes of energy-yielding nutrients during pregnancy was attributable to a higher intake of PUFA by $1.3 \mathrm{~g}(95 \%$ CI $0 \cdot 2,2 \cdot 4)$ and by $0.5 \%$ energy $(95 \%$ CI $0.1,0.8)$ and to a lower intake of SFA by $0.8 \%$ energy $(95 \%$ CI $-1.4,-0.4)$ in the intervention compared to the control group (Fig. 1). In addition, the intake of dietary fibre was higher by $1.8 \mathrm{~g}$ (95\% CI $0 \cdot 1,3.4)$ in the intervention group than in the controls. Although no difference was observed between women receiving and not receiving dietary counselling in MUFA intake, over the pregnancy the intake was $4.7 \mathrm{~g}(95 \%$ CI $2 \cdot 1,7.4)$ and $1.6 \%$ energy $(95 \%$ CI $0.8,2.4)$ higher in the second trimester of pregnancy in the intervention compared to the control group.

The daily intakes of vitamins and minerals from diet, and total intake derived from diet and supplements, are shown in Table 5. Altogether, $96 \%$ of women had used at least one dietary supplement during pregnancy $(P=0.34$ between the groups), the use being $68 \%$ in the first, $82 \%$ in the second and $89 \%$ in the third trimester $(P<0.001$ between trimesters).

Table 2. Proportion (\%) of women consuming the provided food products during the 12-week period between study visits obtained by interview and from 3-day food records in the intervention group

\begin{tabular}{|c|c|c|c|c|c|c|}
\hline & \multicolumn{2}{|c|}{ Second trimester } & \multirow[b]{2}{*}{$P^{*}$} & \multicolumn{2}{|c|}{ Third trimester } & \multirow[b]{2}{*}{$P^{*}$} \\
\hline & Interview & Food record & & Interview & Food record & \\
\hline Spreads $\dagger$ & 100 & 84 & NS & 100 & 84 & NS \\
\hline Cheese with modified fat content & 93 & 48 & 0.01 & 92 & 39 & 0.02 \\
\hline Salad dressing & 71 & 46 & $<0.001$ & 68 & 44 & $<0.001$ \\
\hline Cereal product & 96 & 73 & 0.01 & 96 & 81 & 0.02 \\
\hline
\end{tabular}

${ }^{*} \chi^{2}$ test between methods of estimating food product consumption.

†Low erucic acid rapeseed oil-based soft margarines and soft cheese. 
Table 3. Daily consumption of foods $(\mathrm{g})$ in the intervention $(n 140)$ and the control $(n$ 69) groups in each trimester of pregnancy (Mean values and $95 \% \mathrm{Cl}$ )

\begin{tabular}{|c|c|c|c|c|c|c|c|c|c|c|c|c|c|}
\hline & \multicolumn{4}{|c|}{ First termester } & \multicolumn{4}{|c|}{ Second trimester } & \multicolumn{4}{|c|}{ Third trimester } & \multirow[b]{3}{*}{$P^{\star}$} \\
\hline & \multicolumn{2}{|c|}{ Intervention } & \multicolumn{2}{|c|}{ Control } & \multicolumn{2}{|c|}{ Intervention } & \multicolumn{2}{|c|}{ Control } & \multicolumn{2}{|c|}{ Intervention } & \multicolumn{2}{|c|}{ Control } & \\
\hline & Mean & $95 \% \mathrm{Cl}$ & Mean & $95 \% \mathrm{Cl}$ & Mean & $95 \% \mathrm{Cl}$ & Mean & $95 \% \mathrm{Cl}$ & Mean & $95 \% \mathrm{Cl}$ & Mean & $95 \% \mathrm{Cl}$ & \\
\hline Grain products & 218 & 207,229 & 218 & 204,232 & 223 & 214,233 & 220 & 205,234 & 231 & 220,241 & 230 & 213,247 & NS \\
\hline Milk products & 531 & 499,563 & 471 & 427,515 & 545 & 513,578 & 542 & 493,591 & 558 & 527,590 & 580 & 527,632 & NS \\
\hline Meat products & 113 & 104,122 & 116 & 104,127 & 115 & 106,123 & 114 & 101,127 & 108 & 99,115 & 123 & 111,134 & NS \\
\hline Fish products & 24 & 19,29 & 29 & 21,37 & 28 & 22,33 & 27 & 20,34 & 29 & 23,35 & 20 & 14,26 & NS \\
\hline Vegetables & 295 & 277,312 & 295 & 271,318 & 304 & 283,326 & 260 & 237,283 & 287 & 270,303 & 263 & 241,284 & 0.03 \\
\hline Fruits & 353 & 326,379 & 275 & 245,305 & 348 & 323,373 & 297 & 261,333 & 368 & 344,393 & 321 & 286,356 & $<0.001$ \\
\hline Butter & 6 & 5,7 & 6 & 5,7 & 2 & 2,3 & 6 & 5,8 & 3 & 2,3 & 8 & 6,9 & $<0.001$ \\
\hline Soft margarines & 15 & 13,16 & 16 & 14,18 & 22 & 21,24 & 17 & 14,20 & 20 & 18,21 & 16 & 14,17 & 0.002 \\
\hline Vegetable oils & 10 & 9,12 & 10 & 8,12 & 13 & 12,15 & 8 & 6,9 & 12 & 11,14 & 10 & 8,12 & 0.003 \\
\hline Cheese & 55 & 51,60 & 54 & 47,62 & 49 & 45,54 & 48 & 43,53 & 41 & 38,44 & 54 & 47,61 & NS \\
\hline Sugar and sweets & 33 & 29,37 & 32 & 26,37 & 31 & 27,34 & 32 & 26,37 & 33 & 29,37 & 31 & 26,36 & NS \\
\hline
\end{tabular}

${ }^{\star}$ Repeated-measures ANOVA group effect.

Vitamin D (89\% of the women), iron $(73 \%)$, combination preparations comprising several vitamins and minerals $(68 \%)$ and calcium (47\%) were the supplements used most frequently. Additionally, assessed separately for wintertime (October to March), when vitamin D supplementation is recommended, $87 \%$ of the women had used this supplement.

When the intakes of nutrients as a proportion of the recommended intake were compared between the groups, the intakes of vitamin $\mathrm{E}(55 \%$ and $53 \%$ in the first, $67 \%$ and $53 \%$ in the second and $65 \%$ and $57 \%$ in the third trimester of pregnancy in the intervention and control groups, respectively, $P=0.001$ group effect), folate $(62 \%$ and $56 \%$ in the first, $63 \%$ and $56 \%$ in the second and $60 \%$ and $60 \%$ in the third trimester of pregnancy, respectively, $P=0.04$ group effect) and ascorbic acid (179\% and $150 \%$ in the first, $179 \%$ and $151 \%$ in the second and $183 \%$ and $170 \%$ in the third trimester of pregnancy, respectively, $P=0.01$ group effect) were higher in the intervention group compared to the control group, while no difference emerged between the groups for other nutrients (data not shown). Comparably, dietary intake of vitamin E was $1.4 \mathrm{mg}(95 \%$ CI $0.6,2 \cdot 2)$, folate $20.9 \mu \mathrm{g}(95 \%$ CI $0.8,41.0)$ and ascorbic acid $19.8 \mathrm{mg}(95 \%$ CI $3.5,36 \cdot 0)$ and total intake of vitamin E was $2.1 \mathrm{mg}(95 \%$ CI $0.5,3.8)$ higher in the intervention group compared to the controls.

\section{Discussion}

The present study is the first to apply a combined approach of dietary counselling and provision of food products for use at home in pregnant women in an attempt to encourage changes in food intake and consequently in nutrient intake. Dietary counselling resulted in increased consumption of vegetables, fruits, soft margarines and vegetable oils and decreased consumption of butter, and consequently resulted in higher intakes of PUFA, dietary fibre, vitamin $\mathrm{E}$ and ascorbic acid and folate and lower SFA intake in women receiving dietary counselling compared to those not receiving counselling. These changes have been associated with health benefits with the potential to counteract lifestyle-related chronic conditions such as
CVD and diabetes (World Health Organization, 2003). With respect to pregnancy, an additional advantage may be achieved because the mother's dietary habits are known to influence the health and well-being of both the mother (Gunderson et al. 2000; Vasan et al. 2001) and the fetus or child (Godfrey \& Barker, 2000), which we are further evaluating in an ongoing study.

The mean overall weight gain during pregnancy was $14.9 \mathrm{~kg}$ and the total weight gain during pregnancy was associated with energy intake, suggesting an adequate energy intake by the pregnant women, However, the intake of energy remained less than the estimated requirements, as observed previously (Rogers et al. 1998; Borah Giddens et al. 2000; Swensen et al. 2001; Turner et al. 2003). The discrepancy between intake and estimated energy requirements has been explained by a decrease in physical activity towards the end of pregnancy (Dufour et al. 1999; Kopp-Hoolihan et al. 1999), which was not, however, consistently shown in our study. Another explanation may be an adaptation towards conserving energy, as energy balance studies have found a maintenance of weight gain during pregnancy, despite higher energy expenditure in comparison to energy intake (Kopp-Hoolihan et al. 1999). Supporting previous observations (Dufour et al. 1999; Kopp-Hoolihan et al. 1999; King, 2000), our study also questions the validity of using the current estimated energy requirements during pregnancy, which seem to be too high. Concomitantly, the limitations of the food record method used for the analysis of dietary intake need to be taken into consideration, as underestimation of energy intake or inaccurate reporting may occur (Caan et al. 2004), possibly influencing the reported energy intake.

The mean intake of most nutrients was in accordance with the dietary recommendations, except that the intakes of vitamins $\mathrm{D}$ and $\mathrm{E}$ and folate were less than recommended, as was also observed previously (Erkkola et al. 1998; Rogers et al. 1998; Swensen et al. 2001; Pick et al. 2005). Low intake of these vitamins during pregnancy is of concern in view of their health-related effects. Low intakes of folate and vitamin $\mathrm{E}$ have been associated with an increased risk of neural tube defect in the fetus (Scholl \& Johnson, 2000) 
Table 4. Daily dietary intakes of energy, energy-yielding nutrients and dietary fibre in the intervention $(n 140)$ and the control ( $n$ 69) group in each trimester of pregnancy (Mean values and $95 \% \mathrm{Cl}$ )

\begin{tabular}{|c|c|c|c|c|c|c|c|c|c|c|c|c|c|}
\hline & \multicolumn{4}{|c|}{ First trimester } & \multicolumn{4}{|c|}{ Second trimester } & \multicolumn{4}{|c|}{ Third trimester } & \multirow[b]{3}{*}{$P \dagger$} \\
\hline & \multicolumn{2}{|c|}{ Intervention } & \multicolumn{2}{|c|}{ Control } & \multicolumn{2}{|c|}{ Intervention } & \multicolumn{2}{|c|}{ Control } & \multicolumn{2}{|c|}{ Intervention } & \multicolumn{2}{|c|}{ Control } & \\
\hline & Mean & $95 \% \mathrm{Cl}$ & Mean & $95 \% \mathrm{Cl}$ & Mean & $95 \% \mathrm{Cl}$ & Mean & $95 \% \mathrm{Cl}$ & Mean & $95 \% \mathrm{Cl}$ & Mean & $95 \% \mathrm{Cl}$ & \\
\hline Energy (kJ) & 8205 & 7917,8494 & 7863 & 7440,8285 & 8377 & 8072,8682 & 7959 & 7528,8385 & 8026 & 7854,8427 & 8222 & 7729,8719 & NS \\
\hline \multicolumn{14}{|l|}{ Fat } \\
\hline (g) & 70.5 & $67 \cdot 2,74 \cdot 0$ & 69.6 & $64 \cdot 2,75 \cdot 0$ & 74.0 & $70 \cdot 3,77 \cdot 8$ & 67.7 & $62 \cdot 1,73 \cdot 3$ & 67.7 & $64 \cdot 0,71 \cdot 3$ & 70.6 & $64 \cdot 5,76 \cdot 6$ & NS \\
\hline (\% energy) & $32 \cdot 2$ & $31 \cdot 4,33 \cdot 1$ & 32.9 & $31 \cdot 5,34.4$ & 32.9 & $32 \cdot 1,33.9$ & 31.5 & $30 \cdot 1,32 \cdot 9$ & 30.9 & $30 \cdot 0,31 \cdot 9$ & 31.7 & $30 \cdot 3,33 \cdot 3$ & NS \\
\hline \multicolumn{14}{|l|}{ SFA } \\
\hline (g) & $29 \cdot 1$ & $27 \cdot 5,30 \cdot 6$ & 28.5 & $26 \cdot 0,31 \cdot 0$ & 27.5 & $26 \cdot 1,29 \cdot 0$ & $28 \cdot 3$ & $25 \cdot 8,30 \cdot 7$ & $25 \cdot 0$ & $23 \cdot 4,26 \cdot 6$ & 28.8 & $25 \cdot 9,31 \cdot 7$ & NS \\
\hline (\% energy) & $13 \cdot 3$ & $12 \cdot 8,13 \cdot 8$ & 13.5 & $12 \cdot 7,14 \cdot 2$ & $12 \cdot 3$ & $11 \cdot 9,12 \cdot 7$ & $13 \cdot 1$ & $12 \cdot 4,13.9$ & 11.4 & $10.9,11.9$ & 12.8 & $12 \cdot 0,13 \cdot 6$ & 0.01 \\
\hline \multicolumn{14}{|l|}{ MUFA } \\
\hline (g) & 23.5 & $22 \cdot 2,24 \cdot 8$ & 23.5 & $21 \cdot 7,25 \cdot 4$ & 26.6 & $25 \cdot 1,28 \cdot 2$ & 21.9 & $19 \cdot 9,23 \cdot 9$ & 24.0 & $22 \cdot 6,25 \cdot 5$ & $23 \cdot 2$ & $21 \cdot 1,25 \cdot 2$ & NS \\
\hline (\% energy) & $10 \cdot 7$ & $10 \cdot 3,11 \cdot 1$ & $11 \cdot 2$ & $10 \cdot 6,11 \cdot 9$ & 11.8 & $11 \cdot 4,12 \cdot 3$ & $10 \cdot 2$ & $9 \cdot 6,10 \cdot 8$ & 11.0 & $10.5,11.4$ & 10.5 & $9 \cdot 9,11 \cdot 2$ & NS \\
\hline \multicolumn{14}{|l|}{ PUFA } \\
\hline (g) & 11.4 & $10 \cdot 6,12 \cdot 1$ & 11.4 & $10 \cdot 2,12 \cdot 5$ & 13.6 & $12 \cdot 7,14 \cdot 6$ & $10 \cdot 7$ & $9.5,11.9$ & $12 \cdot 7$ & $12 \cdot 0,13 \cdot 5$ & 11.8 & $10 \cdot 5,13 \cdot 1$ & 0.01 \\
\hline (\% energy) & $5 \cdot 2$ & $4 \cdot 9,5 \cdot 5$ & $5 \cdot 3$ & $4 \cdot 0,5 \cdot 7$ & 6.0 & $5 \cdot 8,6 \cdot 3$ & $5 \cdot 0$ & $4 \cdot 6,5 \cdot 3$ & $5 \cdot 8$ & $5 \cdot 6,6 \cdot 1$ & 5.4 & $4.9 \cdot 9,5.9$ & 0.005 \\
\hline \multicolumn{14}{|l|}{ Protein } \\
\hline (g) & $83 \cdot 2$ & $80 \cdot 0,86 \cdot 5$ & 79.8 & $75 \cdot 0,84 \cdot 6$ & 83.4 & $79 \cdot 4,86 \cdot 9$ & 82.5 & $77 \cdot 5,87 \cdot 6$ & 80.5 & $77 \cdot 3,83 \cdot 8$ & $85 \cdot 3$ & $79 \cdot 7,90 \cdot 8$ & NS \\
\hline (\% energy) & $17 \cdot 1$ & $16 \cdot 6,17 \cdot 5$ & 17.1 & $16 \cdot 4,17 \cdot 8$ & $16 \cdot 7$ & $16 \cdot 2,17 \cdot 1$ & $17 \cdot 4$ & $16 \cdot 8,18 \cdot 0$ & $16 \cdot 7$ & $16 \cdot 2,17 \cdot 1$ & 17.5 & $16 \cdot 8,18 \cdot 2$ & NS \\
\hline \multicolumn{14}{|l|}{ Carbohydrates } \\
\hline (g) & 241.7 & $232 \cdot 2,251 \cdot 1$ & $227 \cdot 3$ & $214 \cdot 1,240.5$ & 244.0 & $234 \cdot 5,253 \cdot 4$ & 234.0 & $221 \cdot 6,246 \cdot 3$ & $247 \cdot 1$ & $238 \cdot 2,256 \cdot 0$ & 240.5 & $225 \cdot 4,255 \cdot 6$ & NS \\
\hline (\% energy) & $49 \cdot 3$ & $48 \cdot 3,50 \cdot 2$ & 48.6 & $47 \cdot 1,50 \cdot 1$ & 48.9 & $47 \cdot 9,49 \cdot 9$ & 49.6 & $48 \cdot 1,51 \cdot 1$ & 51.0 & $50 \cdot 0,51 \cdot 9$ & 49.2 & $47 \cdot 6,50 \cdot 9$ & NS \\
\hline Dietary fibre (g) & $20 \cdot 6$ & $19 \cdot 6,21 \cdot 6$ & 19.7 & $18 \cdot 1,21 \cdot 4$ & $22 \cdot 2$ & $21 \cdot 1,23 \cdot 3$ & 19.9 & $18 \cdot 3,21 \cdot 6$ & $22 \cdot 3$ & $21 \cdot 1,23 \cdot 6$ & $20 \cdot 2$ & $18 \cdot 6,21 \cdot 7$ & 0.03 \\
\hline \multicolumn{14}{|l|}{ Sucrose } \\
\hline (g) & $46 \cdot 1$ & $42 \cdot 9,49 \cdot 4$ & 40.5 & $36 \cdot 4,44 \cdot 6$ & $44 \cdot 3$ & $40 \cdot 8,47 \cdot 9$ & $42 \cdot 6$ & $37 \cdot 8,47 \cdot 5$ & $45 \cdot 1$ & $41 \cdot 2,49 \cdot 0$ & $45 \cdot 2$ & $40 \cdot 3,51 \cdot 1$ & NS \\
\hline (\% energy) & 9.4 & $8 \cdot 8,10 \cdot 0$ & 8.6 & $7 \cdot 6,9 \cdot 4$ & 8.8 & $8 \cdot 2,9 \cdot 3$ & 8.9 & $8 \cdot 0,9 \cdot 8$ & 9.1 & $8 \cdot 5,9 \cdot 7$ & 9.0 & $8 \cdot 2,9 \cdot 8$ & NS \\
\hline
\end{tabular}

*Nordic Nutrition Recommendations (NNR) for pregnant women 2004 (Becker et al. 2004). Recommended intake for fat $30 \%$ energy, protein $15 \%$ energy, carbohydrates $55 \%$ energy, SFA $10 \%$ energy, MUFA $10-15 \%$ energy and

PUFA $5-10 \%$ energy.
†Repeated-measures ANOVA group effect. 

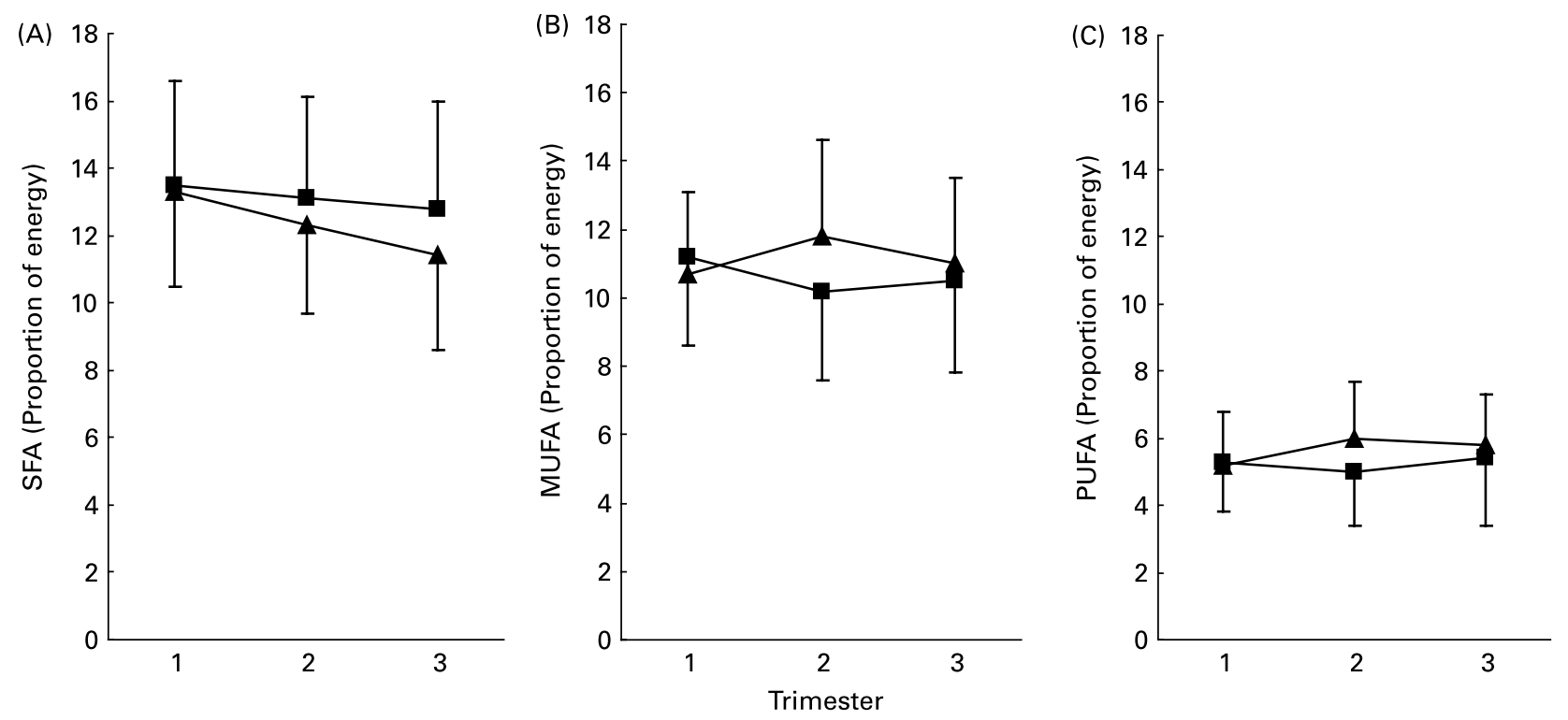

Fig. 1. Intake of (A) SFA, (B) MUFA and (C) PUFA as a proportion of energy intake in the intervention ( $\mathbf{\Delta})$ and the control ( $\mathbf{\square})$ group in each trimester of pregnancy.

and with hypertensive disorders in the mother (Rumbold et al. 2005). However, the higher intakes of folate and vitamin $\mathrm{E}$ in the intervention group in the present study suggest that it may be possible to increase the intake of potentially critical nutrients during pregnancy by means of dietary counselling. For vitamin $\mathrm{D}$, notwithstanding the low dietary intake, the recommendation for pregnant women to use vitamin D supplements during wintertime (10 $\mu \mathrm{g}$ daily from October to March) was achieved. Of the all women, $87 \%$ had used the supplements, which is considerably more than the $33 \%$ observed previously (Erkkola et al. 1998) and speaks in favour of repeated dietary counselling as carried out in the present study. Despite adequate mean dietary intakes of most nutrients in comparison to dietary recommendations, the majority of the women (96\%) had used vitamin and mineral supplements at some stage of pregnancy, and despite counselling, which endeavoured to satisfy the demand for nutrients by diet, the use of supplements did not differ between women receiving dietary counselling or not. This probably reflects women's concern over the well-being of the fetus and of themselves, which is generally thought to be improved by supplement use. However, the use of supplements during pregnancy may not be without risk, and while the long-term effects on pregnant women and the fetus remain unresolved, previous supplementation studies in patients with chronic diseases and in healthy people have shown alarming effects (Bjekovic et al. 2004; Miller et al. 2004).

The recommended intakes of MUFA and PUFA were achieved and, additionally, although higher than recommended, the intake of SFA was lowered in the intervention group. Compared to a previous national study with Finnish women of child-bearing age, the intakes of SFA were considerable lower and the intakes of MUFA and PUFA were higher (Reinivuo et al. 2003). The difference in SFA intake between women receiving and women not receiving dietary counselling was, however, smaller than that observed previously in women with gestational diabetes mellitus who received dietary advice (Gillen \& Tapsell, 2004). Increased motivation to alter dietary habits because of pregnancy-related complications possibly augmented the effect of counselling compared to healthy women in the present study. The longer duration of the study might have affected women's motivation to maintain the recommended diet and consumption of food products provided, as suggested by the improvements in the dietary intake from the first to the second trimester and a tendency to reach the baseline by the third trimester of pregnancy. All pregnant women participating in the study also attended communal well-women clinics, where they might have received dietary counselling by nurses, and thus might have already altered their dietary habits before entry to the study. For ethical reasons and to improve compliance in food record keeping, women in the control group also received feedback on their food records, which may have affected the dietary intake. Nevertheless, bearing in mind the presented limitations of the study, the focused dietary counselling supported by food products led to favourable changes in dietary intake.

Women with atopic disease may run a risk of nutritional inadequacy as they may limit their diet due to symptoms of the disease. In the present study atopic disease had no adverse impact on dietary intake, in contrast to previous observations, in which the intake of ascorbic acid was lower (Hoppu et al. 2000) and the intakes of total fat and SFA were higher in women with atopic disease compared to those without (Hoppu et al. 2000; Solvoll et al. 2000; Trak-Fellermeier et al. 2004). The positive skin prick test results for foods in the present study were mainly for nuts and also for potatoes and carrots, which are usually tolerated cooked, and not for nutritionally important foods, such as grain products or milk. Additionally, the present results indicate that food cannot be used in manipulating symptoms of atopic disease as commonly as thought and may also reflect the awareness of mothers following a balanced diet during pregnancy. 
Table 5. Daily dietary and total intakes of vitamins and minerals in the intervention and the control group in each trimester of pregnancy ${ }^{\star}$

(Mean values and $95 \% \mathrm{Cl}$ )

\begin{tabular}{|c|c|c|c|c|c|c|c|c|c|c|c|c|c|}
\hline & \multicolumn{4}{|c|}{ First trimester } & \multicolumn{4}{|c|}{ Second trimester } & \multicolumn{4}{|c|}{ Third trimester } & \multirow[b]{3}{*}{$P \dagger$} \\
\hline & \multicolumn{2}{|c|}{ Intervention } & \multicolumn{2}{|c|}{ Control } & \multicolumn{2}{|c|}{ Intervention } & \multicolumn{2}{|c|}{ Control } & \multicolumn{2}{|c|}{ Intervention } & \multicolumn{2}{|c|}{ Control } & \\
\hline & Mean & $95 \% \mathrm{Cl}$ & Mean & $95 \% \mathrm{Cl}$ & Mean & $95 \% \mathrm{Cl}$ & Mean & $95 \% \mathrm{Cl}$ & Mean & $95 \% \mathrm{Cl}$ & Mean & $95 \% \mathrm{Cl}$ & \\
\hline \multicolumn{14}{|c|}{ Retinol $(\mu \mathrm{g})$} \\
\hline Diet & 973.7 & $838 \cdot 2,1007 \cdot 7$ & $883 \cdot 2$ & $760 \cdot 9,1005 \cdot 5$ & 958.8 & $857.7,1059.9$ & 777.5 & $689 \cdot 9,865 \cdot 1$ & 954.1 & $845 \cdot 5,1062 \cdot 7$ & 941.0 & $694 \cdot 8,1187 \cdot 3$ & NS \\
\hline Total & 1187.8 & $987 \cdot 5,1388 \cdot 1$ & 1506.4 & $766 \cdot 3,2246 \cdot 4$ & 1563.0 & $1362 \cdot 6,1763 \cdot 3$ & $867 \cdot 4$ & $1571 \cdot 6,3306 \cdot 3$ & $1119 \cdot 6$ & $429 \cdot 4,1809 \cdot 7$ & $982 \cdot 2$ & $303 \cdot 1,1661 \cdot 2$ & NS \\
\hline \multicolumn{14}{|c|}{ Cholecalciferol $(\mu \mathrm{g})$} \\
\hline Diet & $4 \cdot 3$ & $3 \cdot 8,4 \cdot 8$ & $5 \cdot 1$ & $4 \cdot 3,6 \cdot 0$ & 5.5 & $4 \cdot 8,6 \cdot 3$ & 5.4 & $4 \cdot 5,6 \cdot 3$ & $5 \cdot 7$ & $5 \cdot 0,6 \cdot 3$ & 4.9 & $4 \cdot 3,5 \cdot 5$ & NS \\
\hline Total & 10.9 & $9.9,11.8$ & 11.5 & $10 \cdot 3,12 \cdot 7$ & $13 \cdot 2$ & $12 \cdot 0,14 \cdot 3$ & 11.2 & $10 \cdot 0,12 \cdot 5$ & $12 \cdot 5$ & $11 \cdot 6,13 \cdot 4$ & 11.8 & $10 \cdot 8,12 \cdot 8$ & NS \\
\hline \multicolumn{14}{|c|}{ Vitamin E (mg) } \\
\hline Diet & $9 \cdot 4$ & $8.9,10 \cdot 0$ & $9 \cdot 1$ & $8 \cdot 4,9 \cdot 8$ & 11.5 & $10 \cdot 8,12 \cdot 1$ & 9.0 & $8 \cdot 1,9 \cdot 8$ & 11.0 & $10 \cdot 4,11 \cdot 6$ & 9.6 & $8 \cdot 6,10 \cdot 7$ & 0.001 \\
\hline Total & $19 \cdot 4$ & $18 \cdot 5,20 \cdot 2$ & 18.4 & $16 \cdot 9,19 \cdot 7$ & $22 \cdot 0$ & $20 \cdot 8,23 \cdot 3$ & 18.4 & $17 \cdot 1,19 \cdot 8$ & 20.7 & $19 \cdot 6,21 \cdot 8$ & 19.5 & $17 \cdot 4,21 \cdot 6$ & 0.01 \\
\hline \multicolumn{14}{|c|}{ Thiamin (mg) } \\
\hline Diet & 1.5 & $1 \cdot 4,1 \cdot 6$ & 1.4 & $1 \cdot 3,1.5$ & 1.6 & $1.5,1 \cdot 6$ & 1.5 & $1 \cdot 4,1 \cdot 6$ & 1.5 & $1.4,1 \cdot 6$ & 1.5 & $1 \cdot 4,1 \cdot 7$ & NS \\
\hline Total & 4.0 & $3 \cdot 4,4.5$ & 4.4 & $3 \cdot 1,5 \cdot 6$ & 4.0 & $3 \cdot 5,4 \cdot 6$ & 3.9 & $3 \cdot 3,4 \cdot 5$ & 3.9 & $3 \cdot 4,4 \cdot 3$ & $4 \cdot 3$ & $3 \cdot 6,5 \cdot 1$ & NS \\
\hline \multicolumn{14}{|c|}{ Riboflavin (mg) } \\
\hline Diet & $2 \cdot 1$ & $2 \cdot 0,2 \cdot 2$ & 1.9 & $1 \cdot 8,2 \cdot 1$ & $2 \cdot 1$ & $2 \cdot 0,2 \cdot 2$ & $2 \cdot 1$ & $1 \cdot 9,2 \cdot 3$ & $2 \cdot 1$ & $2 \cdot 0,2 \cdot 2$ & $2 \cdot 2$ & $2 \cdot 0,2 \cdot 4$ & NS \\
\hline Total & 5.5 & $4 \cdot 5,6 \cdot 4$ & $5 \cdot 6$ & $4 \cdot 1,7 \cdot 2$ & 5.6 & $4 \cdot 6,6 \cdot 5$ & 6.0 & $4.4,7.5$ & 4.7 & $4 \cdot 2,5 \cdot 3$ & $5 \cdot 2$ & $4 \cdot 3,6 \cdot 0$ & NS \\
\hline \multicolumn{14}{|c|}{ Niacin (mg) } \\
\hline Diet & $16 \cdot 8$ & $15 \cdot 9,17 \cdot 7$ & $16 \cdot 7$ & $15 \cdot 6,17 \cdot 9$ & $17 \cdot 2$ & $16 \cdot 3,18 \cdot 1$ & $17 \cdot 2$ & $15 \cdot 7,18 \cdot 6$ & $17 \cdot 2$ & $16 \cdot 3,18 \cdot 1$ & 17.6 & $16 \cdot 3,19 \cdot 0$ & NS \\
\hline Total & $41 \cdot 2$ & $35 \cdot 0,47 \cdot 4$ & 43.6 & $33 \cdot 8,53 \cdot 3$ & 40.1 & $35 \cdot 4,44 \cdot 8$ & 39.8 & $32 \cdot 4,47 \cdot 3$ & 38.6 & $34 \cdot 1,43 \cdot 1$ & 38.5 & $35 \cdot 3,41 \cdot 6$ & NS \\
\hline \multicolumn{14}{|c|}{ Vitamin $B_{12}(\mu \mathrm{g})$} \\
\hline Diet & 7.0 & $5 \cdot 6,8 \cdot 3$ & 6.6 & $4 \cdot 9,8 \cdot 3$ & $5 \cdot 8$ & $5 \cdot 0,6 \cdot 5$ & $6 \cdot 3$ & $5 \cdot 5,7 \cdot 0$ & $6 \cdot 1$ & $5 \cdot 2,7 \cdot 0$ & 7.1 & $5 \cdot 4,8.9$ & NS \\
\hline Total & $25 \cdot 1$ & $9 \cdot 2,41 \cdot 1$ & $21 \cdot 3$ & $3 \cdot 9,38 \cdot 6$ & $12 \cdot 0$ & $4.7,19 \cdot 2$ & $16 \cdot 2$ & $2 \cdot 2,30 \cdot 1$ & $12 \cdot 0$ & $5 \cdot 3,18 \cdot 6$ & 9.1 & $8 \cdot 0,10 \cdot 2$ & NS \\
\hline \multicolumn{14}{|c|}{ Folate $(\mu \mathrm{g})$} \\
\hline Diet & $308 \cdot 4$ & $294 \cdot 4,322 \cdot 4$ & 279.6 & $260 \cdot 0,299 \cdot 1$ & 313.5 & $297 \cdot 8,329 \cdot 2$ & 280.5 & $262 \cdot 4,298 \cdot 7$ & $301 \cdot 4$ & $287 \cdot 1,315 \cdot 7$ & $300 \cdot 4$ & $281 \cdot 2,319 \cdot 7$ & 0.04 \\
\hline Total & 582.3 & $543 \cdot 1,621 \cdot 6$ & 564.2 & $504 \cdot 8,623 \cdot 6$ & 588.0 & $557 \cdot 2,618 \cdot 8$ & 542.5 & $496 \cdot 0,590 \cdot 0$ & $546 \cdot 2$ & $515 \cdot 6,576 \cdot 8$ & 554.3 & $514 \cdot 2,594 \cdot 7$ & NS \\
\hline \multicolumn{14}{|c|}{ Ascorbic acid (mg) } \\
\hline Diet & $152 \cdot 2$ & $137 \cdot 9,166 \cdot 4$ & $127 \cdot 6$ & $113 \cdot 9,141 \cdot 3$ & $152 \cdot 2$ & $139 \cdot 2,165 \cdot 2$ & $128 \cdot 7$ & $111 \cdot 9,145 \cdot 5$ & $155 \cdot 8$ & $143 \cdot 6,167 \cdot 9$ & 144.5 & $127 \cdot 5,161 \cdot 6$ & 0.01 \\
\hline Total & 232.9 & $197 \cdot 0,268 \cdot 9$ & 218.6 & $175 \cdot 7,261 \cdot 4$ & $261 \cdot 3$ & $228 \cdot 2,294 \cdot 5$ & 216.0 & $178 \cdot 8,253 \cdot 3$ & 251.6 & $224 \cdot 6,278 \cdot 5$ & 231.6 & $197 \cdot 2,264 \cdot 5$ & NS \\
\hline \multicolumn{14}{|c|}{ Calcium (mg) } \\
\hline Diet & $1300 \cdot 9$ & $1233 \cdot 9,1367 \cdot 9$ & 1188.4 & $1091 \cdot 7,1285 \cdot 1$ & $1224 \cdot 1$ & $1152 \cdot 2,1295 \cdot 9$ & $1275 \cdot 7$ & $1158 \cdot 6,1392 \cdot 8$ & $1197 \cdot 8$ & $1135 \cdot 0,1260 \cdot 6$ & $1304 \cdot 3$ & $1179 \cdot 9,1428 \cdot 7$ & NS \\
\hline Total & 1697.9 & $1564 \cdot 7,1831 \cdot 2$ & 1576.9 & $1344.0,1759.7$ & $1594 \cdot 7$ & $1482 \cdot 1,1707 \cdot 3$ & $1640 \cdot 6$ & $1472 \cdot 9,1808 \cdot 2$ & $1668 \cdot 8$ & $1546 \cdot 5,1791 \cdot 0$ & $1762 \cdot 9$ & $1536 \cdot 8,1989 \cdot 0$ & NS \\
\hline \multicolumn{14}{|c|}{ Iron (mg) } \\
\hline Diet & $12 \cdot 3$ & $11 \cdot 8,12 \cdot 8$ & $12 \cdot 0$ & $11 \cdot 3,12 \cdot 8$ & 12.5 & $12 \cdot 0,13 \cdot 0$ & $12 \cdot 6$ & $11 \cdot 6,13 \cdot 5$ & $12 \cdot 7$ & $12 \cdot 1,13 \cdot 2$ & $12 \cdot 0$ & $11 \cdot 3,12 \cdot 7$ & NS \\
\hline Total & $59 \cdot 2$ & $35 \cdot 5,66 \cdot 4$ & 28.5 & $16 \cdot 9,42 \cdot 4$ & 97.4 & $85 \cdot 6,109 \cdot 2$ & $95 \cdot 7$ & $77 \cdot 4,114.0$ & $100 \cdot 2$ & $91 \cdot 0,109 \cdot 4$ & $95 \cdot 2$ & $78 \cdot 5,111 \cdot 8$ & NS \\
\hline \multicolumn{14}{|c|}{ Zinc (mg) } \\
\hline Diet & $12 \cdot 2$ & $11 \cdot 7,12 \cdot 6$ & 11.7 & $11 \cdot 1,12 \cdot 4$ & $12 \cdot 1$ & $11 \cdot 6,12 \cdot 6$ & $12 \cdot 0$ & $11 \cdot 2,12 \cdot 8$ & $11 \cdot 8$ & $11 \cdot 3,12 \cdot 3$ & $12 \cdot 2$ & $11 \cdot 4,13 \cdot 0$ & NS \\
\hline Total & 23.9 & $22 \cdot 8,25 \cdot 0$ & $24 \cdot 3$ & $22 \cdot 6,26 \cdot 0$ & 24.7 & $23 \cdot 6,25 \cdot 8$ & $25 \cdot 8$ & $24 \cdot 1,27 \cdot 5$ & $24 \cdot 1$ & $23 \cdot 0,25 \cdot 1$ & 24.4 & $23 \cdot 1,26 \cdot 0$ & NS \\
\hline
\end{tabular}

${ }^{*}$ Nordic Nutrition Recommendations (NNR) for pregnant women 2004 (Becker et al. 2004). Recommended intake for retinol $800 \mu \mathrm{g}$, cholecalciferol $10 \mu \mathrm{g}$, vitamin E $10 \mathrm{mg}$, thiamin $1.5 \mathrm{mg}$, riboflavin $1.6 \mathrm{mg}$, niacin $17 \mathrm{mg}$, vitamin $\mathrm{B}_{12}$ $2.0 \mu \mathrm{g}$, folate $500 \mu \mathrm{g}$, ascorbic acid $85 \mathrm{mg}$, calcium $900 \mathrm{mg}$, zinc $9 \mathrm{mg}$.

$\dagger$ Repeated-measures ANOVA group effect. 
The present study shows that the novel approach of dietary counselling combined with food products can improve the achievement of a dietary intake conforming with that recommended. Dietary counselling during pregnancy, if applied in a larger health-care setting, may reduce pregnancy-related disorders, promote the growth and development of the fetus and child and result in long-term health benefits in both. Furthermore, dietary counselling has been shown to be a cost-effective method in health care to prevent and provide care in lifestyle-related diseases (Franz et al. 1995; Delahanty et al. 2001; Murray et al. 2003). An advantage may be achieved by developing counselling practices in health care (Huurre et al. in press), thus providing a foundation for continuing healthy eating habits extending to the postpartum period, an aspect that we are exploring in an ongoing study. In conclusion, the findings of the present study suggest that dietary counselling of pregnant women, combined with provision of appropriate food products, is of importance in modifying food and nutrient intake with potential health benefits, presenting a challenge to food manufacturers in providing supporting products.

\section{Acknowledgements}

We thank the women who participated in the present study, Ulla-Maija Eriksson, Johanna Hvitfelt-Koskelainen, Sari Laksio and Sanna Hirvonen for participating in study visits, and Robert MacGilleon for revision of the English text. We gratefully acknowledged financial support from the Academy of Finland, the Social Insurance Institution of Finland, the Sigrid Juselius Foundation and the Juho Vainio Foundation, and provision of food products by Raisio plc.

\section{References}

Abrams B, Altman SL \& Pickett KE (2000) Pregnancy weight gain: still controversial. Am J Clin Nutr 71, Suppl., 1233S-1241S.

Arvola T \& Holmberg-Marttila D (1999) Benefits and risks of elimination diets. Ann Med 31, 293-298.

Becker W, Lyhne N, Pedersen A, et al. (2004) Nordic Nutrition Recommendations 2004 - integrating nutrition and physical activity. Scand J Nutr 48, 178-187.

Bjekovic G, Nikolova D, Simonett RG \& Gluud C (2004) Antioxidant supplements for prevention of gastrointestinal cancers: a systemic review and meta-analysis. Lancet 364, 1219-1928.

Borah Giddens J, Krug SK, Tsang RC, Guo S, Miodovnik M \& Prada JA (2000) Pregnant adolescent and adult women have similarly low intakes of selected nutrients. $J$ Am Diet Assoc 100, $1334-1340$.

Caan B, Ballard-Barbash R, Slattery M, et al. (2004) Low energy reporting may increase in intervention participants enrolled in dietary intervention trials. J Am Diet Assoc 104, 357-366.

Delahanty LM, Sonnenberg LM, Hayden D \& Nathan DM (2001) Clinical and cost outcomes of medical nutrition therapy for hypercholesterolemia: a controlled trial. J Am Diet Assoc 101, $1012-1023$.

Dufour DL, Reina JC \& Spurr GB (1999) Energy intake and expenditure of free-living, pregnant Colombian women in an urban setting. Am J Clin Nutr 70, 269-276.

Erkkola M, Karppinen M, Järvinen A, Knip M \& Virtanen SM (1998) Folate, vitamin D, and iron intakes are low among pregnant Finnish women. Eur J Clin Nutr 52, 742-748.
Franz MJ, Splett PL, Monk A, Barry B, McClain K, Weaver T, Upham P, Bergenstal R \& Mazze RS (1995) Cost-effectiveness of medical nutritional therapy provided by dietitians for persons with non-insulin-dependent diabetes mellitus. J Am Diet Assoc 95, 1018-1024.

Gillen LJ \& Tapsell LC (2004) Advice that includes food sources of unsaturated fat supports future risk management of gestational diabetes mellitus. J Am Diet Assoc 104, 1863-1867.

Godfrey KM \& Barker DJP (2000) Fetal nutrition and adult disease. Am J Clin Nutr 71, Suppl., 1344-1352.

Gunderson EP, Abrams B \& Selvin S (2000) The relative importance of gestational gain and maternal characteristics associated with the risk of becoming overweight after pregnancy. Int J Obes 24, 1660-1668.

Hoppu U, Kalliomäki M \& Isolauri E (2000) Maternal diet rich in saturated fat during breastfeeding is associated with atopic sensitization of the infant. Eur J Clin Nutr 54, 702-705.

Huurre A, Laitinen K, Hoppu U \& Isolauri E (in press). How practice meets guidelines: evaluation of nutrition counseling in Finnish well-women and well-baby clinics. Acta Paed.

Kalliomäki M, Salminen S, Arvilommi H, Kero P, Koskinen P \& Isolauri E (2001) Probiotics in primary prevention of atopic disease: a randomised placebo-controlled trial. Lancet 357, 1076-1079.

King JC (2000) Physiology of pregnancy and nutrient metabolism. Am J Clin Nutr 71, Suppl., 1218S-1225S.

Kopp-Hoolihan LE, van Loan MD, Wong WW \& King JC (1999) Longitudinal assessment of energy balance in well-nourished, pregnant women. Am J Clin Nutr 69, 697-704.

Laitinen K, Sallinen J, Linderborg K \& Isolauri E (2006) Serum, cheek cell and breast milk fatty acid compositions in infants with atopic and nonatopic eczema. Clin Exp Allergy 36, 166-173.

Miller ER, Pastor-Barriuso R, Dalal D, Riemersma RA, Appel LJ \& Guallar E (2004) Meta-analysis: high-dosage vitamin E supplementation may increase all-cause mortality. Ann Intern Med 142, 37-46.

Murray CL, Lauer JA, Hutubessy RC, Niessen L, Tomijima N, Rodgers A, Lawes CM \& Evans DB (2003) Effectiveness and costs of interventions to lower systolic blood pressure and cholesterol: a global and regional analysis on reduction of cardiovasculardisease risk. Lancet 361, 717-725.

Nordic Working Group on Diet and Nutrition (1996) Nordic Nutrition Recommendations. Scand J Nutr 40, 161-165.

Pallard F, Herranz L, Garcia-Ingelmo T, Grande C, Martin-Vaquero P, Janez M \& Gonzalez A (1999) Early postpartum metabolic assessment in women with prior gestational diabetes. Diabetes Care 22, $1053-1058$.

Pick ME, Edwards M, Moreau D \& Ryan EA (2005) Assessment of diet quality in pregnant women using the healthy eating index. $J$ Am Diet Assoc 105, 240-246.

Reinivuo H, Männistö S, Tapanainen H \& Pakkala H (2003) Intake of nutrients. In The National FINDIET 2002 Study, pp. 49-51 [S Männistö, M-L Ovaskainen and L Valsta, editors]. Helsinki: Publications of the National Public Health Institute.

Rogers I \& Emmett P the ALSPAC study team (1998) Diet during pregnancy in a population of pregnant women in South West England. Eur J Clin Nutr 52, 246-250.

Rumbold AR, Maats FHE \& Crowther CA (2005) Dietary intake of vita$\min \mathrm{C}$ and vitamin $\mathrm{E}$ and the development of hypertensive disorders of pregnancy. Eur J Obstet Gynecol Reprod Biol 119, 67-71.

Rössner S \& Öhlin A (1995) Pregnancy as a risk factor for obesity: lessons from the Stockholm Pregnancy and Weight Development Study. Obes Res 3, S267-S275.

Scholl TO \& Johnson WG (2000) Folic acid: influence on the outcome of pregnancy. Am J Clin Nutr 7, Suppl., 1295S-1303S.

Sicherer SH (2002) The impact of maternal diets during breastfeeding on the prevention of food allergy. Allergy Clin Immunol 2, $207-210$ 
Solvoll K, Soyland E, Sandstad B \& Drevon CA (2000) Dietary habits among patients with atopic dermatitis. Eur J Clin Nutr 54, 93-97.

Swensen AR, Harnack LJ \& Ross JA (2001) Nutritional assessment of pregnant women enrolled in the Special Supplemental Program for Women, Infants and Children (WIC). J Am Diet Assoc 101, 903-908.

Trak-Fellermeier MA, Brasche S, Winkler G, Koletzko B \& Heinrich J (2004) Food and fatty acid intake and atopic disease in adults. Eur Respir J 23, 575-582.

Turner RE, Langkamp-Henken B, Littell RC, Lukowski MJ \& Suarez MF (2003) Comparing nutrient intake from food to the estimated average requirements shows middle- to upper-income pregnant women lack iron and possibly magnesium. J Am Diet Assoc 103, 461-466.

Vasan RS, Larson MG, Leip EP, Kannel WB \& Levy D (2001) Assessment of frequency of progression to hypertension in non-hypertensive participants in the Framingham Heart Study: a cohort study. Lancet 358, 1682-1686.

Verma A, Boney CM, Tucker R \& Vohr BR (2002) Insulin resistance syndrome in women with prior history of gestational diabetes mellitus. J Clin Endocrinol Metab 87, 3227-3235.

World Health Organization (1985) Energy and Protein Requirements. Joint FAO/WHO/UNU Expert Consultation. Switzerland: WHO.

World Health Organization (1988) Measuring Obesity: classification and Description of Anthropometric Data. WHO Consultation on the Epidemiology of Obesity. Copenhagen: WHO Regional Office for Europe, Nutrition Unit.

World Health Organization (2003) Diet, Nutrition and the Prevention of Chronic Diseases. Joint WHO/FAO Expert Consultation. WHO Technical Report Series no. 916 Geneva: WHO. 